\begin{tabular}{|c|c|c|}
\hline \multirow{3}{*}{$\begin{array}{r}\text { Case Reports in } \\
\text { Gastroenterology }\end{array}$} & \multirow{2}{*}{\multicolumn{2}{|c|}{ Case Rep Gastroenterol 2016;10:151-156 }} \\
\hline & & \\
\hline & $\begin{array}{l}\text { 10.1159/000445738 } \\
\text { Puotisned oninne: VIlay 2, } 2016\end{array}$ & $\begin{array}{l}\text { (c) } 2016 \text { The Author(s) } \\
\text { Published by S. Karger AG, Basel } \\
1662-0631 / 16 / 0101-0151 \$ 39.50 / 0 \\
\text { www.karger.com/crg }\end{array}$ \\
\hline
\end{tabular}

\title{
Efficacy of Self-Expandable Metallic Stent Inserted for Refractory Hemorrhage of Duodenal Cancer
}

\author{
Takashi Orii Yukihiko Karasawa Hiroe Kitahara Masaki Yoshimura \\ Motohiro Okumura \\ Department of Surgery, Showa Inan General Hospital, Komagane, Japan
}

\section{Keywords}

Self-expandable metallic stent $\cdot$ Malignant gastrointestinal tract hemorrhage $\cdot$ Duodenal cancer

\begin{abstract}
Because of advances in the technology of gastrointestinal endoscopy and improvements in the quality of stents, it has become routine to place a stent as palliative therapy for malignant gastrointestinal obstruction. On the other hand, stent placement for malignant gastrointestinal hemorrhage has scarcely been reported, although it may be performed for hemorrhage of the esophageal varicose vein. We recently experienced a patient with refractory hemorrhage from an unresectable duodenal cancer who underwent placement of a selfexpandable metallic stent (SEMS) and thereafter had no recurrence of the hemorrhage. A 46year-old man underwent laparotomy to radically resect a cancer in the third portion of the duodenum, which invaded widely to the superior mesenteric vein and its branches and was considered unresectable. After stomach-partitioning gastrojejunostomy was performed, chemotherapy was initiated according to the regimen of chemotherapy of far advanced gastric cancer. One year and 4 months after induction of chemotherapy, gastrointestinal hemorrhage occurred. Upper gastrointestinal endoscopy revealed the hemorrhage oozing from the duodenal cancer, and endoscopic hemostasis, such as injection of hypertonic saline epinephrine and argon plasma coagulation, was unsuccessful. Twenty days after emergence of the hemorrhage, an endoscopic covered SEMS was placed with confirmation by fluoroscopy. Immediately after placement of the stent, the tarry stool stopped and the anemia ceased to
\end{abstract}

\section{KARGER}




\section{Case Reports in Gastroenterology}

Case Rep Gastroenterol 2016;10:151-156

(c) 2016 The Author(s). Published by S. Karger AG, Basel www.karger.com/crg

Orii et al.: Efficacy of Self-Expandable Metallic Stent Inserted for Refractory Hemorrhage of Duodenal Cancer

progress. The recurrence of the hemorrhage has not been confirmed without migration of the stent. SEMS is an effective hemostatic procedure for malignant refractory hemorrhage.

(C) 2016 The Author(s)

Published by S. Karger AG, Basel

\section{Introduction}

Because of progress in technology in gastrointestinal (GI) endoscopy and improvements in the quality of stents, GI stenting as a palliative therapy for malignant GI obstruction has undergone a remarkable development. For acute obstructions caused by GI malignant disease, previously, rescue from the worsening condition was only obtained by invasive surgical operations, such as construction of a stoma or a bypass operation, even for patients with malnutrition and systemic inflammatory response syndrome. Today, patients can be relieved of their obstruction symptoms promptly and less invasively by placement of a stent, a procedure that is routinely performed [1]. In addition to being used as palliative therapy for advanced colon cancer, the efficacy of a stent as a bridging therapy to surgery has also been reported [2].

On the other hand, GI hemorrhage from advanced malignant tumors is sometimes difficult to control by endoscopic hemostasis, such as local injection of hemostatic materials, coagulation by an electronic device, or embolization of the feeding artery, but stenting treatment has rarely been applied to hemorrhages.

Herein, we report an experience with the placement of a covered self-expandable metallic stent (SEMS) and confirm the efficacy of stenting for intractable malignant hemorrhage from unresectable duodenal cancer.

\section{Case Report}

A 46-year-old man visited our Department of Gastroenterology because of aggravating epigastralgia. Upper GI endoscopy revealed a tumor in the third portion of the duodenum, which was diagnosed as duodenal adenocarcinoma by histopathology of the biopsied specimen. Because computerized tomography showed the duodenal cancer with swelling of regional lymph nodes but without distant metastases (fig. 1), the disease was judged to be radically resectable. Although we planned to perform a pancreaticoduodenectomy, we gave up on the planned operation after exploration around the tumor because extensive invasion to the superior mesenteric vein was confirmed. We completed the surgery after performing stomach-partitioning gastrojejunostomy to prevent possible malignant obstruction and hemorrhage in the future.

After the surgery, the patient underwent DCS (docetaxel, cisplatin, and S-1) therapy as first-line chemotherapy according to that recommended for gastric cancer, and the state of the disease continued to be stable without distant metastasis and local progression after sixteen courses of therapy.

One year and 4 months after initiation of chemotherapy, because hematochezia and mild syncope appeared and the laboratory data showed severe anemia (hemoglobin $5.5 \mathrm{~g} / \mathrm{dl}$ ), he was suspected to be suffering from GI bleeding and was admitted to the hospital urgently. An upper GI endoscopy identified the hemorrhage, oozing from the duodenal cancer. Endoscopic hemostasis techniques, such as hypertonic saline epinephrine solution and argon plasma coagulation, were unsuccessful because the exact location of the bleeding could not be iden- 
Orii et al.: Efficacy of Self-Expandable Metallic Stent Inserted for Refractory Hemorrhage of Duodenal Cancer

tified. Intermittent bleeding persisted every 4 to 5 days and was treated by a blood transfusion each time.

Twenty days after the first emergence of the hemorrhage, a partially covered SEMS (Niti-S Pyloric \& Duodenal Combi Stent, $10.5 \mathrm{Fr}, 20 \times 10 \mathrm{~mm}$, Taewoong Medical) was inserted and placed over the lesion (fig. 2, fig. 3), exerting hemostasis by applying pressure on the tumor surface. Soon after the placement of the stent, anemia progression stopped and hematochezia disappeared. Thereafter, chemotherapy was continued for about 10 months without any sign of recurrent hemorrhage or migration of the stent.

\section{Discussion}

Placement of a stent is performed for obstruction of the GI tract from the esophagus [3] and stomach [4] to the colorectal region [5], and a clinical practice guideline on this use has already been published [6]. The indication for a stent has been extended not only to malignant obstruction but also to treatment for benign stenosis and postoperative leakage [7]. It is also applied as bridging therapy to radical surgery [2] because it can relieve malnutrition from a long-term fasting state during placement of an ileus tube, and avoid an urgent colostomy under high-risk conditions, which contributes to diminishing the incidence of colostomy during radical colectomy and reducing postoperative infectious complications.

For obstruction of the GI tract, we can use plastic stents or SEMS. Although historically plastic stents, made of rigid polyvinyl, were used for GI obstructions, both morbidity and mortality after insertion of plastic stents are higher than after SEMS placement because traumatic dilation of the stenotic portion is sometimes required before placement of a plastic stent that has a fixed diameter [8]. Consequently, plastic stents have rarely been used since the 1990s when uncovered SEMS first became available. SEMS are generally packaged in a compressed form and constrained around a delivery device, making dilation unnecessary and reducing the risks of perforation, obstruction, or migration, which can occur with plastic stents [9].

Because of the uncovered structure of SEMS when they were first introduced, the open mesh architecture caused tumor ingrowth and re-occlusion in $14 \%$ of cases [10]. A covered SEMS was developed to overcome this disadvantage. In their meta-analysis, Pan et al. [11] reported that the occlusion rate was $8.6 \%$, which was significantly lower than that of uncovered SEMS at $21.7 \%$. However, covered SEMS migrate more frequently than uncovered SEMS (18.3 vs. $4.1 \%$, respectively) because covering the outer surface of SEMS may prevent the mesh from embedding into the surrounding tissue. The effect of both stents is equal in palliative treatment of malignant obstruction of the GI tract, so it is necessary to select one depending on the clinical situation [12].

It is almost impossible to find any reports about stenting treatments for malignant GI hemorrhage, although there are some positive reports about refractory bleeding after endoscopic varicose vein ligation and sclerotherapy for esophageal bleeding [13]. Only two case reports could be identified: one, by Yen et al. [14], was a hemorrhage from a duodenal cancer with multiple liver metastases, and the other, by D'Souza et al. [15], was uncontrollable refractory bleeding from a duodenal bulb lesion invaded by local recurrence of posthepatectomized hepatocellular carcinoma. Both cases succeeded in hemostasis by placement of covered SEMS. In this presented case, a covered SEMS was placed, as in the former two cases, in order to cease the malignant hemorrhage from a duodenal cancer. The stent continues to work effectively without any migratory complications due to intestinal peristalsis. 
Orii et al.: Efficacy of Self-Expandable Metallic Stent Inserted for Refractory Hemorrhage of Duodenal Cancer

A stomach-partitioning gastrojejunostomy bypass, which results in the structure passing very little food, is supposed to contribute to the prevention of stent migration.

A patient with uncontrollable and refractory malignant hemorrhage from the third portion of the duodenum acquired a better clinical course by the placement of a covered SEMS. Although stenting treatment for malignant hemorrhage of the GI tract is still not common, it is a reasonable procedure that compresses a wide bleeding lesion in a plane, and it may become one of the most effective treatments for malignant GI hemorrhage.

\section{Statement of Ethics}

The subject gave his informed consent, and the Ethics Committee of Showa Inan General Hospital approved the study protocol.

\section{Disclosure Statement}

The authors have no financial conflicts of interest concerning the manuscript to disclose.

\section{References}

1 Kochar R, Shah N: Enteral stents: from esoghagus to colon. Gastrointest Endosc 2013;78:913-918.

-2 Cirocchi R, Farinella E, Trastulli S, Desiderio J, Listoriti C, Boselli C, Parisi A, Noya G, Sagar J: Safety and efficacy of endoscopic colonic stenting as a bridge to surgery in the management of intestinal obstruction due to left colon and rectal cancer: a systematic review and meta-analysis. Surg Oncol 2013;22:14-21.

-3 Kim JY, Kim SG, Lim JH, Im JP, Kim JS, Jung HC: Clinical outcomes of esophageal stents in patients with malignant esophageal obstruction according to palliative additional treatment. J Dig Dis 2015;16:575584 .

4 Boskoski I, Tringali A, Familiari P, Mutignani M, Costamagna G: Self-expandable metallic stents for malignant gastric outlet obstruction. Adv Ther 2010;27:691-703.

-5 Carcía-Cano J: Colorectal stenting as first-line treatment in acute colonic obstruction. World J Gastrointest Endosc 2013;5:495-501.

-6 van Hooft JE, van Halsema EE, Vanbiervliet G, Beets-Tan RS, DeWitt JM, Donnellan F, Dumonceau JM, Glynne-Jones RG, Hassan C, Jimenez-Perez J, Meisner S, Muthusamy VR, Parker MC, Regimbeau JM, Sabbagh C, Sagar J, Tanis PJ, Vandervoort J, Webster GJ, Manes G, Barthet MA, Repici A; European Society of Gastrointestinal Endoscopy: Self-expandable metal stents for obstructing colonic and extracolonic cancer: European Society of Gastrointestinal Endoscopy (ESGE) Clinical Guideline. Endoscopy 2014;46:990-1053.

-7 Sharaiha RZ, Kim KJ, Singh VK, Lennon AM, Amateau SK, Shin EJ, Canto MI, Kalloo AN, Khashab MA: Endoscopic stenting for benign upper gastrointestinal stricture and leak. Surg Endosc 2014;28:178184.

8 Kim SG, Yang CH: Upper gastrointestinal stent. Clin Endosc 2012;45:386-391.

-9 Park JS, Jeong S, Lee DH: Recent advances in gastrointestinal stent development. Clin Endosc 2015;48:209-215.

10 Knyrim K, Wagner HJ, Bethge N, Keymling M, Vakil N: A controlled trial of an expansile metal stent for palliation of esophageal obstruction due to inoperable cancer. N Engl J Med 1993;329:1302-1307.

-11 Pan YM, Pan J, Guo LK, Qiu M, Zhang JJ: Covered versus uncovered self-expandable metallic stents for palliation of malignant gastric outlet obstruction: a systematic review and meta-analysis. BMC Gastroenterol 2014;14:170-177.

12 Yang Z, Wu Q, Wang F, Ye X, Qi X, Fan D: A systematic review and meta-analysis of randomized trial and prospective studied comparing covered and bare self-expandable metal stents for the treatment of malignant obstruction in the digestive tract. Int J Med Sci 2013;10:825-835.

-13 Müller M, Seufferlein T, Perkhofer L, Wagner M, Kleger A: Self-expandable metal stents for persisting esophageal variceal bleeding after band ligation or infection-therapy: a retrospective study. PLoS One 2015;10:e0126525. 


\title{
Case Reports in Gastroenterology
}

\begin{tabular}{l|l}
\hline Case Rep Gastroenterol 2016;10:151-156 \\
\hline $10.1159 / 000445738$ & $\begin{array}{l}\text { C 2016 The Author(s). Published by S. Karger AG, Basel } \\
\text { www.karger.com/crg }\end{array}$ \\
\hline
\end{tabular}

Orii et al.: Efficacy of Self-Expandable Metallic Stent Inserted for Refractory Hemorrhage of Duodenal Cancer

\begin{abstract}
14 Yen HH, Chen YY, Su PY: Successful use of a fully covered metal stent for refractory bleeding from a duodenal cancer. Endoscopy 2015;47:E34-E35.

15 D’Souza PM, Sandha GS, Teshima CW: Refractory bleeding from a malignant duodenal ulcer treated with placement of a fully-covered gastroduodenal stent. Dig Dis Sci 2013;58:3359-3361.
\end{abstract}

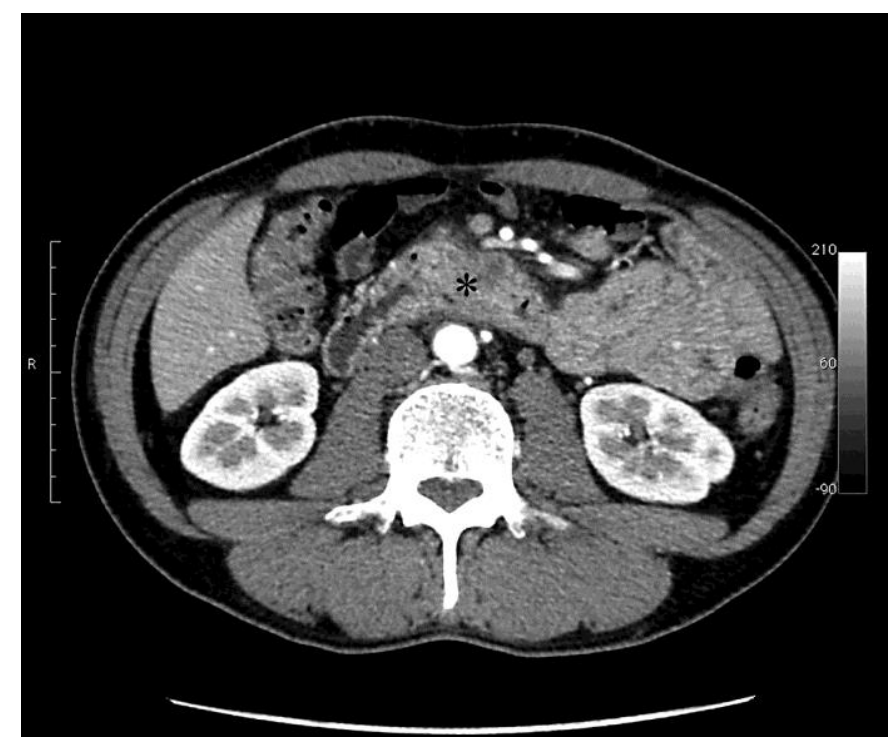

Fig. 1. Image of computerized tomography on the patient's first visit to our hospital. The asterisk indicates the cancer in the third portion of the duodenum.

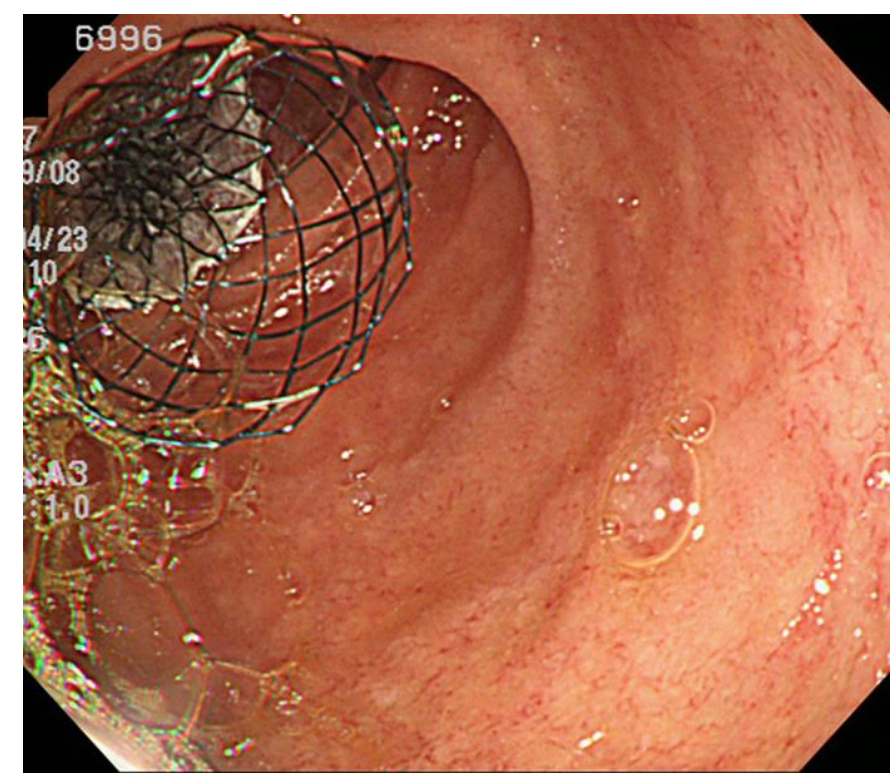

Fig. 2. Endoscopic photograph of the placement of the covered SEMS at the duodenal cancer. 


\begin{tabular}{ll|l} 
Case Reports in & $\begin{array}{l}\text { Case Rep Gastroenterol 2016;10:151-156 } \\
\text { Gastroenterology }\end{array}$ & $\begin{array}{l}\text { ○ 2016 The Author(s). Published by S. Karger AG, Basel } \\
\text { www.karger.com/crg }\end{array}$ \\
\cline { 2 - 2 } & $\begin{array}{l}\text { Orii et al.: Efficacy of Self-Expandable Metallic Stent Inserted for Refractory Hemorrhage } \\
\text { of Duodenal Cancer }\end{array}$
\end{tabular}

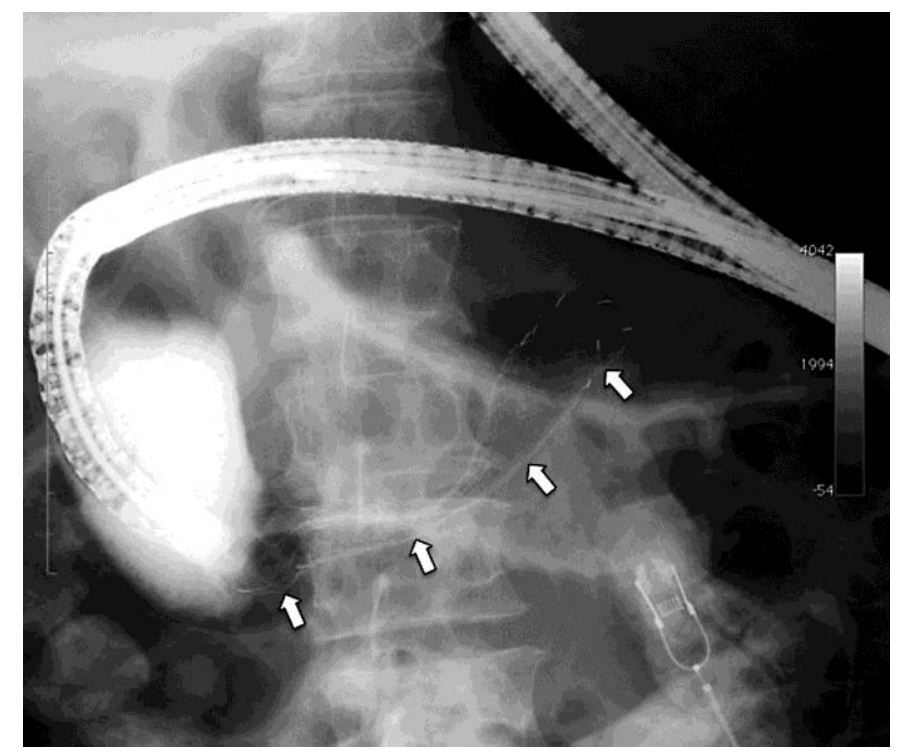

Fig. 3. Image of X-ray fluoroscopy of the placement of the covered SEMS at the duodenal cancer. The arrows indicate the SEMS, placed in the third portion of the duodenum. 